\title{
Stable Beneficial Group Activity Formation
}

\author{
Noor Sami Al-Anbaki \\ Department of Computer Science \\ King Abdullah II School for \\ Information Technology \\ University of Jordan \\ Amman-Jordan
}

\author{
Azzam Sleit \\ Department of Computer Science \\ King Abdullah II School for \\ Information Technology \\ University of Jordan \\ Amman-Jordan
}

\author{
Ahmed Sharieh \\ Department of Computer Science \\ King Abdullah II School for \\ Information Technology \\ University of Jordan \\ Amman-Jordan
}

\begin{abstract}
Computational models are one of the very powerful tools for expressing everyday situations that are derived from human interactions. In this paper, an investigation of the problem of forming beneficial groups based on the members' preferences and the coordinator's own strategy is presented. It is assumed that a coordinator has a good intention behind trimming members' preferences to meet the ultimate goal of forming the group. His strategy is justified and evaluated by Nash stability. There are two variations of the problem: the Anonymous Stable Beneficial Group Activity Formation and the General Stable Beneficial Group Activity Formation. The computational complexity of solving both variations has been analyzed. Finding stable groups needs non-polynomial time algorithm to be solved. A polynomial time solution is presented and enhanced with examples.
\end{abstract}

Keywords - computational models; group formation; members' preferences; Nash stability

\section{INTRODUCTION}

Capturing human behavior and translating it into a model has been the area of research since centuries. The motivation was to build systems that can percept, learn, adapt and take right decisions as well as predict future actions.

This seed plants itself deeply into science, it produced rich mathematical social sciences that had empowered the introduction of social computing science.

Many powerful systems were created as the result of merging social behavior and computational models, examples are: emails, social networks, online gaming, political parties formation, healthcare systems, speaker identification, query expansion techniques [1][7][17],etc.

One of the most interesting areas in this perspective is collective intelligence that refers to the kind of intelligence that is aroused as an effect of the collaborative efforts of many agents to achieve a single goal taking into account competition among them [11]. This concept (although not so named) was referred to in Hedonic Coalitions that was introduced in 1980 [6]. It considered how social coalitions are structured to meet certain preferences. A concept that is rooted in the work of Marquis de Condorcet in 1785, who investigated the probability of making a correct decision by the cooperation of several members [5]. Figure 1 shows the fields of science that branches from collective intelligence [18][12].

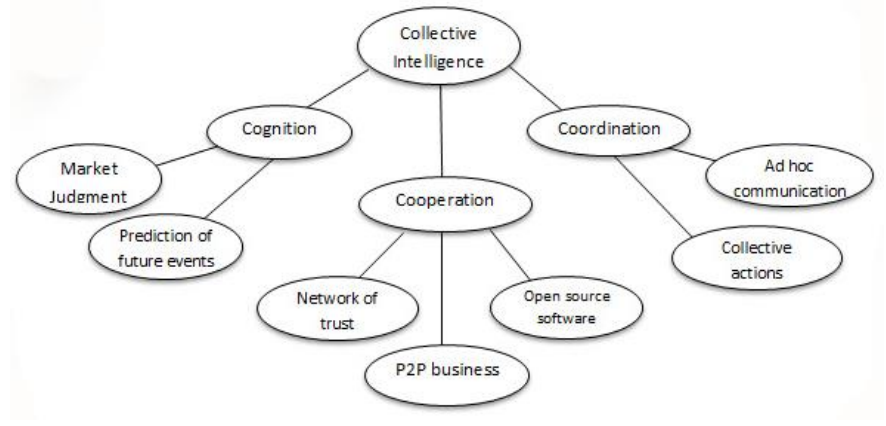

Fig. 1. Collective Intelligence Branches

In the scope of this paper, an investigation of the area of beneficial group activities formation that can be classified under coordinating collective actions is presented.

Scheduling a set of activities has been studied thoughtfully in the literature; one of the new trends in this field is how to schedule activities that each of them should compromise a set of agents.

To formulate this problem, let's consider the social situation that an event coordinator is trying to organize multiple distributed activities that are held in different places at different time intervals. There are no precedence relationship between these activities. They are supposed to be independent on each other; they don't share the same resources.

The coordinator's responsibility is to invite/assign one or more agent to each activity. Agents are not considered as peers rather each agent is supposed to contribute in that activity by a certain score/weight/benefit. Thus, the organizer's goal is to invite/assign as many agents as possible to maximize the amount of contribution i.e. benefit of the activity.

The coordinator should consider the agents' preferences for both the activity and the number of participants in that activity, thus the coordinator should assign agents to activities on basis of their preferences over group size.

Each agent is allowed to have preferences over the identities of other invitees, e.g. one agent might only come if his/her colleague is coming and may not prefer to come if a competitor agent comes. 
The coordinator should make sure that each agent's preferences are met but without contradicting with the ultimate goal of forming the group i.e. maximizing benefit.

Consider the situation where a professor is trying to create multiple research groups on different topics within his field, for example. One of the main concerns when forming such assignments is Stability. It is desirable in many systems that contain scheduling, QoS, clustering, data mining [2][14][16], pattern matching [15], etc. But, it is not always possible to maintain a stable assignment. This motivates investigating the problem and evaluating the complexity of finding a feasible solution.

The paper is organized as follow: Section II presents related literature. Section III demonstrates the Stable beneficial Group Activity Formation Problem. The Anonymous variation of the problem is investigated in section IV along with definitions and notations in addition to examples and algorithms to solve the problem. Section V introduces the Stable beneficial Group Activity Formation Problem along with its definitions, example and algorithm. The conclusion is given in section VI.

\section{RELATED LITRETURE}

Group formation itself has been studied thoughtfully in the literature, different algorithms were proposed to best cluster the members into groups based on attributes they hold [13].

The General Group Activity Selection Problem (GASP) was formally introduced in [4]. An organizer tries to organize several activities, each activity is accomplished by several agents. An agent can participate in exactly one activity at a time, the agent is allowed to select an activity to participate in and the preferred group size for that activity. The authors analyzed the computational complexity of this problem in different cases.

The authors in [8] introduced the Stable Group Scheduling Problem where an organizer is trying to schedule an event that happens over multiple time slot. An agent is allowed to choose the desired time slot to join event and the preferred group size for the activity in that time slot. They analyzed the complexity of this problem for both the non-strategic agents (i.e. agents that reveal their preferences without further modifications) and strategic agents (agents that may change their preferences afterwards).

They found that for the non-strategic agent's variation, a polynomial time algorithm that determines whether a stable schedule exists, and if it does, determine the maximum number of schedules exist.

They extend their work in [9], by introducing the Stable Invitation Problem in two variations: the anonymous and nonanonymous. They consider the problem of how to invite multiple agents to a single event taking into account their preferences over a number of invitees; and who the invitees are. They provide a number of complexity results with respect to stability, and also consider strategic behavior of the agents.

In [3], Darmann re-introduced the General Group Activity Selection Problem, considering the agents' ordinal preferences where each agent can determine the (activity, group size) pair. He analyzed the computational complexity for finding a stable assignment using k-approval scores and considering Nash and core stability.

The approach in this work differs from the approaches stated above by considering the situation of more than one independent activity. To best reflect the problem, the organizer himself has a goal to form the group/invitation which is maximizing benefit. Furthermore, in this approach the agents are not treated as peers, instead, each agent is assumed to contribute in the group to some extent.

It is worth mentioning that these problems are inspired by the Hedonic Games [6].

\section{STABLE BENEFICIAL GROUP ACTIVITY FORMATION PROBLEM}

A professor creates multiple research groups on different topics within his field, he/she invites students to join these groups. His/her objective is to maximize the benefit from this group by:

1) maximizing the number of attendees in each group.

2) inviting only students that has knowledge in the area.

Students are allowed to have preferences over the group size as well as the colleagues in the group. The professor's strategic considers Nash stability in forming stable groups. There are two variations of the problem, the Anonymous Beneficial Group Activity Formation ABGA and the General Beneficial Group Activity Formation GBGA.

\section{ANONYMOUS BENEFICIAL GROUP ACTIVITY FORMATION ABGA}

In this variation, students don't have preferences over identities of the invitees but they only care about the size of the research group they are invited into.

\section{A. Definitions and Notations}

Definition 1.An instance of the Beneficial Group Activity Formation ABGA is a tuple (A, E, P) where,

$A=\left\{a_{1}, a_{2}, \ldots, a_{n}\right\}$ is a set of $n$ agents,

$\mathrm{E}=\left\{\mathrm{e}_{1}, \mathrm{e}_{2}, \ldots, \mathrm{e}_{\mathrm{m}}\right\}$ is a set of $\mathrm{m}$ activities (Research Groups)

$\mathrm{P}$ is an n-tuple of preferences of agents where $\mathrm{P}=\left(\mathrm{P}_{1}\right.$, $\left.\mathrm{P}_{2}, \ldots, \mathrm{P}_{\mathrm{n}}\right)$. For each agent $\mathrm{a}_{\mathrm{i}}$, define $\mathrm{P}_{\mathrm{i}}$ to be a total preorder $\left(\succcurlyeq_{i}\right)$ on the set of preferences, the agents may prefer not coming if $\mathrm{p}_{\mathrm{i}}=0$.

For any $\mathrm{p}_{1}, \mathrm{p}_{2} \in(\mathrm{P} \backslash\{0\}), \mathrm{p}_{1} \succcurlyeq_{\mathrm{i}} \mathrm{p}_{2}$ means that agent $\mathrm{a}_{\mathrm{i}}$ prefers joining the group if the number of attendees in the group is $p_{1}$ (including himself) to attending if the number of attendees is $\mathrm{p}_{2}$ attendees (including himself).

Any subset of $\mathrm{A}$ is a solution to ABGA-instance (N,E,P), is called G a 'Beneficial Group'.

Definition 2. Agent's benefit, in this example, student's knowledge within the area of the group is defined in terms of (courses studied, interest, publications) and is expressed as a score in the knowledge-matrix. The higher the score is, the 
more knowledge the student has within this area. Knowledge matrix $B$ is a two-dimensional matrix of size $(|\mathrm{A}| *|\mathrm{E}|)$ i.e. $\left(\mathrm{n}^{*} \mathrm{~m}\right)$. The professor invites all students that are expected to maximize the contribution of the group, by inviting only students whose knowledge within the area of the group exceeds T, a threshold score determined by the professor.

$\forall \mathrm{a}_{\mathrm{i}} \in \mathrm{G}, \mathrm{B}\left(\mathrm{a}_{\mathrm{i}}, \mathrm{E}_{\mathrm{j}}\right)>\mathrm{T}$.

Definition 3. The objective is to invite a subset of agents subject to stability constraints considering agents' preferences over group size. An instance (A, E, P) is said to be Nash stable, if:

1) If everyone who's invited is willing to participate, then $\mathrm{G}$ is Individually-Rational.

$\mathrm{G}$ is Individually-Rational (IR) if $\forall \mathrm{a}_{\mathrm{i}} \in \mathrm{G},|\mathrm{G}| \geqslant 0 \wedge \mathrm{B}$ (ai , $\left.\mathrm{E}_{\mathrm{k}}\right)>\mathrm{T}$.

2) If everyone who's not invited is unwilling to join, $G$ is Regret-Free RF if $\forall \mathrm{a}_{\mathrm{i}} \notin \mathrm{G}, 0 \geqslant(|\mathrm{G}|+1)$.

In other words, Individual-Rationality means that all the invited students prefer to come to not coming and has knowledge in the area of the research group as their contribution exceeds T. While Regret-Free means that all agents who are not invited, don't prefer to come.

$\mathrm{G}$ is said to be Nash stable if it is both IR and RF.

The professor's goal is to maximize the number of members in stable beneficial groups.

\section{B. Examples of $A B G A$}

Example1.Example of anonymous preferences.

- A Basketball team preferences over group size.

$$
\text { A1: } 10>5>0>1,2,3,4^{1}
$$

- A Soccer team preferences over group size.

$$
\text { A2:22>11>0>1,2,3,4,5,6,7,8,9,10 }
$$

Example2.Finding a Stable Group.

Consider agents $a_{1}, a_{2}$, $a_{3}$ have knowledge in two areas and the professor is trying to compose two Research Groups $G_{1}$ and $\mathrm{G}_{2}$. The students preferences over group size are as follows:

- $\mathrm{P}_{1}: 1>0>2$

- $\mathrm{P}_{2}: 3>0>1$

- $\mathrm{P}_{3}: 2>0>1$

- Inviting no one, i.e. $\mathrm{G}=\{\}$, is not $\mathrm{RF}$ because of $\mathrm{a}_{1}$ whose preference is $(1>0)$, he prefers coming alone to not coming at all.

Recall that $\mathrm{G}$ is RF if $\forall \mathrm{a}_{\mathrm{i}} \notin \mathrm{G}, 0 \geqslant(|\mathrm{G}|+1)$

- Inviting only $\mathrm{a}_{1}$, i.e. $\mathrm{G}=\left\{\mathrm{a}_{1}\right\}$ is not $\mathrm{RF}$ because of $\mathrm{a}_{3}$ whose preference is $(2>0)$, he prefers joining someone

\footnotetext{
${ }^{1}$ a1 prefers joining the basketball team if the number of members (including himself) is 10, more than he prefer joining if the members (including himself) is 5 . And he also prefers joining the team if the number of members (including himself) is 5, more than not coming. And he would rather not come if the number of members (including himself) is less than 5 .
}

else to not coming. Investigate $\mathrm{G}=\left\{\mathrm{a}_{2}, \mathrm{a}_{3}\right\}$, if it is stable, then $G=\left\{a_{1}\right\}$ is stable.

$\mathrm{G}_{1}=\left\{\mathrm{a}_{2}, \mathrm{a}_{3}\right\}$ is stable because it is both IR and RF. Thus $\mathrm{G}_{2}=\left\{\mathrm{a}_{1}\right\}$ is stable.

- Inviting only $\mathrm{a}_{2}$, i.e. $\mathrm{G}=\left\{\mathrm{a}_{2}\right\}$ is not IR because of $\mathrm{a}_{2}$ whose preference is $(0>1)$, he would rather not come to coming alone.

- Inviting only $a_{3}$, i.e. $G=\left\{a_{3}\right\}$ is not IR because of $a_{3}$ $(0>1)$

- Inviting $\mathrm{a}_{1}, \mathrm{a}_{2}$, i.e. $\mathrm{G}=\left\{\mathrm{a}_{1}, \mathrm{a}_{2}\right\}$ is not IR because of $\mathrm{a}_{1}$ preference $(0>2)$, he prefers not coming to coming with only another person.

- Inviting $\mathrm{a}_{1}, \mathrm{a}_{3}$, i.e. $\mathrm{G}=\{\mathrm{a} 1, \mathrm{a} 2\}$ is not IR because of $\mathrm{a} 1$.

- Inviting $\mathrm{a}_{1}, \mathrm{a}_{2}$, i.e. $\mathrm{G}=\left\{\mathrm{a}_{1}, \mathrm{a}_{2}\right\}$ is not IR because of $\mathrm{a}_{1}$.

- It is not possible to invite the three of them as it contradicts the professor's constrain of constructing two groups.

Thus, only one assignment is possible.

$\mathrm{G} 1=\left\{\mathrm{a}_{2}, \mathrm{a}_{3}\right\}$ and $\mathrm{G} 2=\left\{\mathrm{a}_{1}\right\}$.

Example2.Stable Group may not exist

Consider students $\mathrm{A}_{1}$ and $\mathrm{A}_{2}$ are invited to only one Research Group $E_{1}$. Students preferences over group size are as follows:

- $\mathrm{P}_{1}: 1>0>2$

- $\mathrm{P}_{2}: 2>0>1$

- Inviting no one, i.e. $\mathrm{G}=\{\}$, is not $\mathrm{RF}$ because of $\mathrm{a}_{1}$ preference $(1>0)$

- Inviting only $\mathrm{a}_{1}$, i.e. $\mathrm{G}=\left\{\mathrm{a}_{1}\right\}$ is not RF because of $\mathrm{a}_{2}$ preference $(2>0)$.

- Inviting only $a_{2}$, i.e. $G=\left\{a_{2}\right\}$ is not IR because of $a_{2}$ preference $(0>1)$

- Inviting $\mathrm{a}_{1}, \mathrm{a}_{2}$, i.e. $\mathrm{G}=\left\{\mathrm{a}_{1}, \mathrm{a}_{2}\right\}$ is not IR because of $\mathrm{a}_{1}$ preference $(0>2)$

C. ABGA Algorithm and Complexity Analysis

1) Exhaustive Algorithm Complexity

Algorithm 1: To find the maximum number of stable groups

\section{Input:}

1. A set of students.

2. P Students' preferences as tuples.

3. E set of Research Groups.

4. B knowledge matrix.

5. T knowledge threshold.

Output: BG a subset of A

\{ // Definitions

int $\mathrm{n} \quad / /$ number of students

int $\mathrm{m} \quad / /$ number of activities 
int $\mathrm{p} \quad / /$ size of preferences tuple int Students[n] //1-dimension array of students int Activity[m] // 1-dimension array of activities int Benefit $[\mathrm{n}, \mathrm{m}]$

int Pref[n,p] // preferences matrix

$\mathrm{G}[\mathrm{]}, \mathrm{S}[\mathrm{]} / /$ temporary vectors

// Groups construction

For $\mathrm{j}=1$ to $\mathrm{m}$

For $\mathrm{i}=1$ to $\mathrm{n}$

$$
\text { If }(B(i, j)>T)
$$

Then Students $[\mathrm{i}] \in \mathrm{G}_{\mathrm{j}}[]$

//Checking size compatibility of each group

For $\mathrm{j}=1$ to $\mathrm{m}$

PSize $_{\mathrm{j}}=\left|\mathrm{G}_{\mathrm{j}}\right| / /$ preferred size of group

For $\mathrm{i}=1$ to PSize $_{\mathrm{j}}$

\{

\{

For $\mathrm{j}=1$ to $n$

For $\mathrm{k}=1$ to $\mathrm{p}$

If ( $\mathrm{i}=\operatorname{Pref}[\mathrm{j}, \mathrm{k})$ then Students[n] $\in \mathrm{S}_{\mathrm{i}}[\mathrm{]}$

\}

If $\mid \mathrm{S}_{\mathrm{i}}\left[\mathrm{]} \mid=\mathrm{PSize}_{\mathrm{j}}\right.$ then $\mathrm{S}_{\mathrm{i}} \subset \mathrm{BG}_{\mathrm{j}}$ \}

Return $\mathrm{BG}_{\mathrm{j}}$

\}

To check whether a group $\mathrm{G}$ is stable, assuming that the professor invited only beneficial students, consider:

- $\forall \mathrm{a}_{\mathrm{i}} \in \mathrm{G}$, check whether $|\mathrm{G}| \succcurlyeq_{\mathrm{i}} 0$

- $\forall \mathrm{a}_{\mathrm{i}} \notin \mathrm{G}$, check whether $0 \succcurlyeq_{\mathrm{i}}(|\mathrm{G}|+1)$

This checking is repeated at most $|\mathrm{A}| *|\mathrm{E}|$ times, i.e. for each of the agents and groups.

Thus to check all the $2^{\mathrm{n}}$ subsets of A, the algorithm's complexity takes at most $\mathrm{O}\left(\mathrm{n} * \mathrm{~m} * 2^{\mathrm{n}}\right)$ which means that the algorithm needs non-polynomial time to find the solution.

2) Efficient Algorithm Complexity

It is possible to check whether a group $G$ is stable, assuming that the professor invited only beneficial students, then consider Algorithm 2:

Algorithm 2: To find the maximum number of stable groups

\section{Input:}

1. A set of students.

2. P Students' preferences tuple.

3. G set of Research Groups.

4. A professor's preferred group size $\mathrm{X}$.

Output: $\mathrm{G}$ a subset of A

$\{$ For $\mathrm{j}=1$ to $\mathrm{m}$

For $\mathrm{i}=1$ to $\mathrm{n}$

If $\left\{\right.$ Students $\left.[i] \in G_{i}:\left(X \geqslant_{j} 0\right)\right\} \geq X$

If $\left\{\right.$ Students[i] $\left.\in \mathrm{G}_{\mathrm{i}}:\left(0 \geqslant_{\mathrm{j}} \mathrm{X}\right) \wedge\left((\mathrm{X}+1) \geqslant_{\mathrm{j}} 0\right)\right\}=0$

If $\left\{\right.$ Students $\left.[\mathrm{i}] \in \mathrm{G}_{\mathrm{i}}:\left(\mathrm{X} \geqslant_{\mathrm{j}} 0\right) \wedge\left((\mathrm{X}+1) \geqslant_{\mathrm{j}} 0\right)\right\} \leq \mathrm{X}$

Return $\mathrm{G}_{\mathrm{i}}$ is stable
\}

This algorithm takes only $\mathrm{O}\left(\mathrm{m}^{*} \mathrm{n}^{2}\right)$ operations which is so much better than the exhaustive search algorithm.

\section{GENERAL BENEFICIAL Group ACTIVITY Formation PROBLEM GBGA}

This is a generalization of the ABGA. In addition to group size, each student allowed to have preferences over the identities of the colleagues joining the same group:

- Colleagues who is comfortable working with: Wish list

- Colleagues who is undesirable working with: Reject list

The professor strategic is to consider Nash stability in forming stable groups. His/her objective is to maximize the benefit from this group by:

1) maximizing the number of attendees in each group.

2) inviting only students that has knowledge in the area.

\section{A. Definitions and Notations}

An instance of the General Group Activity Formation ABGA is $\left(A, E, P=\left(P_{1}, P_{2}, \ldots, P_{n}\right), W, R\right)$, where

$A=\left\{a_{1}, a_{2}, \ldots, a_{n}\right\}$ is a set of agents.

$\mathrm{E}=\left\{\mathrm{e}_{1}, \mathrm{e}_{2}, \ldots, \mathrm{e}_{\mathrm{m}}\right\}$ is a set of $\mathrm{m}$ activities (Research Groups)

$\mathrm{P}$ is an n-tuple of preferences of agents where $\mathrm{P}=\left(\mathrm{P}_{1}\right.$, $\left.\mathrm{P}_{2}, \ldots, \mathrm{P}_{\mathrm{n}}\right)$. For each agent $\mathrm{a}_{\mathrm{i}}$, define $\mathrm{P}_{\mathrm{i}}$ to be a total preorder $\left(\succcurlyeq_{\mathrm{i}}\right)$ on the set of preferences, the agents may prefer not coming if $\mathrm{p}_{\mathrm{i}}=0$.

$\mathrm{W}_{\mathrm{i}}$ is prefer set of student $\mathrm{a}_{\mathrm{i}}$ where $\mathrm{W}_{\mathrm{i}} \subset \mathrm{A}$

$R_{i}$ is reject set of student $a_{i}$ where $R_{i} \subset A$

Any subset $G$ of $A$ is a solution to GBGAinstance(A,E,P,W,R), $\mathrm{G}$ is a 'Beneficial Group'-

Students are allowed to have preferences over:

- Research group size

- Colleagues who is comfortable working with: W-list

- Colleagues who is undesirable working with: R- list Thus, every potential invitee is either:

- Original-Invitee: invited by the professor as he/she has knowledge within the area or

- Co-Invitee: preferred to be invited by one of the original-invitees as they both have mutual contribution within the area or for any other reasons.

Everyone who is not invited, is not a researcher in the area.

Agents Mutual contribution matrix is defined in terms of two-dimensional matrix $M$ of size $(n * n)$ that represents mutual contribution between agents based on (shared project, publications).

\section{B. Applying Stability Constrains}

The professor's ultimate goal is to collect beneficial students in each group to attain group stability. Although he 
invites only students that has a contribution in the area above a certain threshold, he would agree with an original-invitee to invite a student with less contribution if this co-invitee has previous mutual contribution with the original invitee.

This strategy is adopted from May and Doob work on cooperative learning. They stated that "people who cooperate and work together to achieve shared goals, were more successful in attaining outcomes, than those who strived independently to complete the same goals" [10]. Thus, the professor is willing to:

- not respond to the student's wish to work with a certain colleague if the co-invitee has no knowledge in the area. The professor would agree to invite the coinvitee student $a_{i}$ if his/her contribution within the area of the group is more than $\mathrm{T}$.

If $a_{i} \in W_{j, k} \wedge B\left(a_{i}, E_{k}\right)>T$, then $a_{i} \in G_{j}$, where

$\mathrm{a}_{\mathrm{i}}$ is the co-invitee student

$\mathrm{W}_{\mathrm{j}, \mathrm{k}}$ is the Wish-list of Student $\mathrm{j}$ for activity $\mathrm{K}$

$\mathrm{B}\left(\mathrm{a}_{\mathrm{i}}, \mathrm{E}_{\mathrm{k}}\right)$ is the benefit of student $\mathrm{a}_{\mathrm{i}}$ for the activity $\mathrm{E}_{\mathrm{k}}$

$\mathrm{T}$ is the contribution threshold.

- not respond to the student's wish to reject working with a certain colleague, if the rejected college has knowledge in the area.

If $a_{i} \in R_{j, k} \wedge B\left(a_{i}, E_{j}\right)>T$, then $a_{i} \in G_{j}$,

where $R_{j, k}$ is the Reject-list of Student $j$ for activity $K$

- agrees on the student's wish to work with a certain colleague, if the co-invitee has mutual contribution with the original-invitee even if his/her contribution within the area is $<\mathrm{T}$.

If $a_{i} \in W_{j, k} \wedge\left(B\left(a_{i}, E_{j}\right)<T\right) \wedge\left(M\left(a_{i}, a_{j}\right)>T^{\prime}\right)$, then $a_{i} \in G_{j}$

Where $T^{\prime}$ is a mutual contribution threshold determined by the professor.

\section{GBGA Example}

A professor is trying to create 3 research groups for 3 areas. He/she has 3 students. The contribution threshold is $>4$. The mutual contribution threshold is $>2$. Find the maximum number of groups. The students preferences, contribution and mutual contribution is shown in the matrices in TABLE II.

TABLE I. MUTUAL CONTRIBUTION MATRIX M

\begin{tabular}{|c|c|c|c|}
\hline Agent & a1 & a2 & a3 \\
\hline a1 & 0 & 1 & 5 \\
\hline a2 & 1 & 0 & 7 \\
\hline a3 & 5 & 7 & 0 \\
\hline
\end{tabular}

TABLE II. CONTRIBUTION MATRIX B

\begin{tabular}{|l|l|l|l|}
\hline Agent & Area1 & Area2 & Area3 \\
\hline a1 & 9 & 2 & 7 \\
\hline a2 & 1 & 4 & 3 \\
\hline
\end{tabular}

\begin{tabular}{|l|l|l|l|}
\hline a3 & 6 & 2 & 10 \\
\hline \multicolumn{5}{|c|}{ TABLE III. PREFERENCES MATRIX } \\
\hline Student & Preferred group size & Prefer List & Reject List \\
\hline $\mathrm{a}_{1}$ & $3>2>0$ & $\mathrm{a}_{2}$ & $\mathrm{a}_{3}$ \\
\hline $\mathrm{a}_{2}$ & $2>1>0$ & $\mathrm{a}_{3}$ & 0 \\
\hline $\mathrm{a}_{3}$ & $4>2>0$ & $\mathrm{a}_{1}$ & $\mathrm{a}_{2}$ \\
\hline
\end{tabular}

It is obvious that the preferred size that the three students agree upon is 2 .

For Area1,

- Students $\mathrm{a}_{1}$ and $\mathrm{a}_{3}$ have acceptable contribution scores, they both would be invited.

- $\mathrm{a}_{1} \mathrm{~W}$-list is rejected, because $\mathrm{a}_{2}$ has little contribution in the area and little mutual contribution with a1.

- $\quad a_{1} \mathrm{~W}$-list is rejected, because $\mathrm{a}_{3}$ has good contribution in the area.

- $\mathrm{a}_{3} \mathrm{~W}$-list and R-List are applicable.

- The resultant group is $\mathrm{G} 1=\left\{\mathrm{a}_{1}, \mathrm{a}_{3}\right\}$.

For Area2,

- Only students $a_{2}$ has acceptable contribution score, he is invited, $G_{2}=\left\{a_{2}\right\}$.

- $\mathrm{A}_{2} \mathrm{~W}$-list is accepted as a3 has mutual contribution with $a_{2}>2$. Thus, $G_{2}=\left\{a_{2} \cdot a_{3}\right\}$.

- $\mathrm{A}_{2} \mathrm{R}$-List is empty.

- The resultant group is $\mathrm{G}_{2}=\left\{\mathrm{A}_{2}, \mathrm{~A}_{3}\right\}$.

For Area3,

- Students $\mathrm{a}_{1}$ and $\mathrm{a}_{3}$ have acceptable contribution scores, they both would be invited.

- $\mathrm{a}_{1} \mathrm{~W}$-list is rejected, because $\mathrm{a}_{2}$ has little contribution in the area and little mutual contribution with $\mathrm{a}_{1}$.

- $\mathrm{a}_{1} \mathrm{~W}$-list is rejected, because $\mathrm{a}_{3}$ has good contribution in the area.

- $\quad a_{3} \mathrm{~W}$-list and R-List are applicable.

- The resultant group is $\mathrm{G}_{1}=\left\{\mathrm{a}_{1}, \mathrm{a}_{3}\right\}$.

D. GBGA Algorithm and Complexity Analysis

Algorithm: To find the maximum number of stable groups.

\section{Input:}

1. A set of students.

2. P Students' preferences matrix P.

3. E set of Research Areas.

4. Wish-List W

5. Reject-List R

6. Contribution matrix B

7. Mutual Contribution matrix M.

Output: a subset of $B G \in G$ 


\section{$\{/ /$ Definitions \\ int $\mathrm{n} \quad$ // number of students \\ int $\mathrm{m} \quad / /$ number of activities \\ int $\mathrm{p} \quad / /$ size of preferences tuple \\ int Students[n] //1-dimension array of students \\ int Activity[m] // 1-dimension array of activities \\ int Benefit $[\mathrm{n}, \mathrm{m}]$ \\ int Pref[n,p] // preferences matrix \\ $\mathrm{G}[\mathrm{]}, \mathrm{S}[\mathrm{]} \quad / /$ temporary vectors}

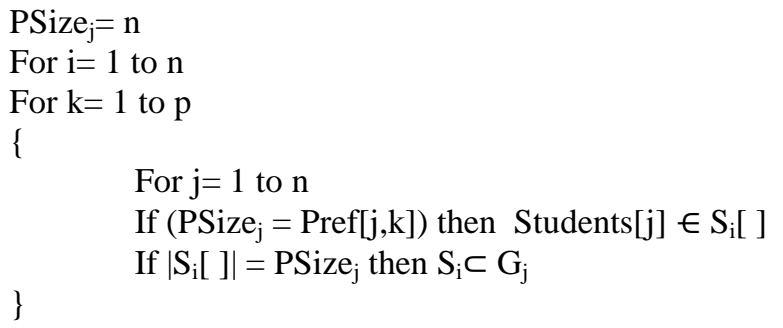

For $\mathrm{k}=1$ to $\mathrm{m}$

For $\mathrm{i}=1$ to $\mid \mathrm{G}_{\mathrm{i}}[\mathrm{]} \mid$

For $\mathrm{j}=1$ to $\left|\mathrm{G}_{\mathrm{i}}[]\right|$

if (Students[i] $\in \mathrm{W}_{\mathrm{k}} \wedge \mathrm{B}(\mathrm{i}, \mathrm{k})>\mathrm{T}$ ) then Students[i] $\in \mathrm{G}_{\mathrm{j}}$

else

If (Students[i] $\in R_{k} \wedge B(i, k)>T$ ) then Students[i] $\in G_{j}$ else

If (Students[i] $\in \mathrm{W}_{\mathrm{k}} \wedge(\mathrm{B}(\mathrm{i}, \mathrm{k})<\mathrm{T}) \wedge \mathrm{M}($ Students[i]

,Students[j]) $>T^{\prime}$ ) then Students[i] $\in \mathrm{G}_{\mathrm{j}}$

\section{Return G}

\}

The GBGA algorithm takes only $\mathrm{O}\left(\mathrm{m}^{*} \mathrm{n} * \mathrm{p}\right)$ operations. It has a polynomial run time complexity.

\section{CONCLUSION AND DISCUSSION}

The main contribution of this work is the analysis of the stable beneficial group activity formation problem considering the members' preferences as well as the coordinator strategy. The coordinator is trying to maintain stability in the groups formed while maximizing the overall benefit and balance those metrics to the members' preferences. The formalism of this problem tried to reflect the natural way of composing beneficial groups without relying upon hard constrains in the traditional way. Two variations of the problem and a their computational complexity are presented.

The proposed algorithm, with polynomial running time achieves the same quality of the exhaustive non-polynomial time algorithm that is used for stable beneficial groups formation. The proposed solution made use of the agents' preferences and coordinator's strategy as delimiters of the problem space.
For future research, it is highly encouraged that the researchers formulate the reflection of further extensions of the problem. Examples of extensions are scheduling those groups in different time slots, considering deadline constrain, and forcing penalties on members who change their group membership, etc.

\section{REFERENCES}

[1] Adwan, O., Sleit, A., Qatawneh, M., Huneiti, A., Khalil, T., \& Abu, A. L. "Implementing a Total Healthcare Enterprise Resource Planning System". Information-An International Interdisciplinary Journal, pp. 3997-4004, 2013.

[2] Almobaideen, W., Al-Khateeb, D., Sleit, A., Qatawneh, M., Qadadeh, K., Al-Khdour, R., \& Hafeeza, H. A. "Improved stability based partially disjoint AOMDV", 2013.

[3] Darmann, A. "Group Activity Selection from Ordinal Preferences". In Algorithmic Decision Theory (pp. 35-51), 2015. Springer International Publishing.

[4] Darmann, A., Elkind, E., Kurz, S., Lang, J., Schauer, J., \& Woeginger, G. "Group activity selection problem". In Internet and Network Economics(pp. 156-169), 2012. Springer Berlin Heidelberg.

[5] Douglas J. Amy."Behind the Ballot Box: A Citizen's Guide to Voting System"s. Greenwood Publishing Group. p. 188, 2000.

[6] Dreze, J. H., \& Greenberg, J. "Hedonic coalitions: Optimality and stability". Econometrica: Journal of the Econometric Society, 987-1003, 1980.

[7] Hammo, B., Sleit, A., \& El-Haj, M. "Effectiveness of query expansion in searching the Holy Quran".The Second International Conference on Arabic Language Processing CITALA'07., Rabat, Morocco, pp. 1-10. 2007.

[8] Lee, H., \& Shoham, Y. "Stable Invitations". arXiv preprint arXiv:1405.7751, 2014.

[9] Lee, H., \& Shoham, Y. "Stable group scheduling". In Proceedings of the 2014 international conference on Autonomous agents and multi-agent systems, pp. 1347-1348, 2014.

[10] May, M. and Doob, L. "Cooperation and Competition". New York: Social Sciences Research Council, 1937.

[11] Pierpaolo, B., et al. "Evaluation of multi-agent systems: Proposal and validation of a metric plan." Transactions on Computational Collective Intelligence VII. Springer Berlin Heidelberg, pp. 198-221, 2012.

[12] Rheingold, H. "Smart mobs: The next social revolution". Basic books, 2007.

[13] Salah, I., Sleit, A., Al-Sharaeh, S., Huneiti, A., \& Obeed, N. "Efficient Method for Assigning Students to Proper Groups". Editorial Advisory Board e,21(2), pp. 249-358, 2005.

[14] Sleit, A., Al-Akhras, M., Juma, I., \& Alian, M. "Applying Ordinal Association Rules for Cleansing Data With Missing Values". Journal of American Science, 5(3),pp. 52-62, 2009.

[15] Sleit, A., AlMobaideen, W., Baarah, A. H., \& Abusitta, A. H. "An efficient pattern matching algorithm". Journal of Applied Sciences, 7(18), pp. 2691-2695, 2007.

[16] Sleit, A., Qatawneh, M., Al-Sharief, M., Al-Jabaly, R., \& Karajeh, O. "Image Clustering using Color, Texture and Shape Features". KSII Transactions on Internet \& Information Systems, 5(1), 2011.

[17] Sleit, A., Serhan, S., \& Nemir, L. "A histogram based speaker identification technique".First International Conference onApplications of Digital Information and Web Technologies, ICADIWTIEEE, pp. 384$388,2008$.

[18] Surowiecki, J. "The wisdom of crowds". Anchor, 2005. 